\title{
The Effect of Sensory Innervation on the Inorganic Component of Bones and Teeth; Experimental Denervation - Review
}

\author{
Ivo Němec ${ }^{1}$, Václav Smrčka ${ }^{2}$, Jaroslav Pokorný ${ }^{3}$ \\ ${ }^{1}$ Department of Otorhinolaryngology and Maxillofacial Surgery, Third Faculty \\ of Medicine, Charles University and Military University Hospital Prague, Prague, \\ Czech Republic; \\ ${ }^{2}$ Institute for History of Medicine and Foreign Languages, First Faculty of Medicine, \\ Charles University, Prague, Czech Republic; Department of Plastic Surgery, First \\ Faculty of Medicine, Charles University and Na Bulovce Hospital, Prague, Czech \\ Republic; \\ ${ }^{3}$ Institute of Physiology, First Faculty of Medicine, Charles University, Prague, \\ Czech Republic \\ Received May 9, 2018; Accepted January 31, 2019.
}

Key words: Bone innervation - Chemical elements - Sensory denervation Laboratory rat

Abstract: The effect of the nervous system on bone remodelling has been
described by many studies. Sensory and autonomic nerves are present in the
bone. Immunohistochemical analysis of the bone have indicated the presence of
neuropeptides and neurotransmitters that act on bone cells through receptors.
Besides carrying sensory information, sensory neurons produce various
neuropeptides playing an important role in maintaining bone and tooth pulp
homeostasis, and dentin formation. Bone tissue and teeth contain organic and
inorganic components. Bone cells enable bone mineralization and ensure its
formation and resorption. Studies focused on the effects of the nervous system
on the bone are proceeded using various ways. Sensory denervation itself can
be achieved using capsaicin causing chemical lesion to the nerve. Surgical ways
of causing only sensory lesion to nerves are substantially limited because many
peripheral nerves are mixed and contain a motor component as well. From this
point of view, the experimental model with transection of inferior alveolar nerve

Mailing Address: Ivo Němec, MD., Department of Otorhinolaryngology and Maxillofacial Surgery, Third Faculty of Medicine, Charles University and Military University Hospital Prague, U Vojenské nemocnice 1200, 16902 Prague 6, Czech Republic; e-mail: Ivo.Nemec@uvn.cz 
is appropriate. This nerve provides sensory innervation of the bone and teeth of the mandible. The purpose of our paper is to provide an overview of the effects exerted by the nervous system on the inorganic component of the bone and teeth, and also to present an overview of the used experimental models. As we assume, the transection of inferior alveolar nerve could be reflected in changed contents and distribution of chemical elements in the bone and teeth of rat mandible. This issue has not been studied so far.

\section{Introduction}

Bone remodelation is a process that goes on throughout the life. This process is slow and is ensured by several hormonal, paracrine/autocrine, mechanical and transcription signals whose targets can be osteoclasts and osteoblasts at various stages of their lifespan. Defects in bone remodelation caused by imbalance between osteoblast and osteoclast activity lead to the development of osteoporosis or osteopetrosis. Both these cases are associated with risk of fractures (Elefteriou, 2005). Various studies of the effects of the nervous system on bone metabolism (Konttinen et al., 1996; García-Castellano et al., 2000; Elefteriou, 2005, 2008; Patel and Elefteriou, 2007; Lerner et al., 2008; Sample et al., 2011; Elefteriou et al., 2014; Wu et al., 2016) and tooth metabolism (Jacobsen and Heyeraas, 1996; Fristad, 1997; Byers et al., 2003; Standring, 2016) have been published. Besides carrying sensory information, sensory neurons also produce various neuropeptides, which play an important role in maintaining bone homeostasis (Wu et al., 2016). Additionally, neuropeptides influence the maintenance of homeostasis in tooth pulp and in dentin formation (Standring, 2016). For example, impact of a transection to inferior alveolar nerve (IAN) on the healing of an alveolar defect and its mineralization has been described in connection with the mandible (Lv et al., 2014). Other authors have published the effect of a lesion to IAN on dentin formation in the first molar in the rat (Jacobsen and Heyeraas, 1996). Bone tissue and teeth (enamel, dentin and cementum) contain an organic and inorganic component (Abou Neel et al., 2016). Calcium is one of essential elements in bones and teeth where it is found predominantly in the form of hydroxyapatite, which also contains phosphorus (Dermience et al., 2015). Calcium metabolism disorders manifest as changes in the structure and properties of bone mass and teeth. Calcium homeostasis is maintained by the activity of osteoclasts, which resorb the bone, thereby increasing serum calcium concentration, and by the concurrent activity of osteoblasts, which are involved in new bone mass formation, thereby decreasing serum calcium concentration (Wilhelm, 2007). Studies of the effects of the nervous system on bone tissue and teeth use various experimental models (Stewart, 1965; Retief and Dreyer, 1969; Torneck and Harnett, 1971; Hoffman and Tade, 1972; Hill et al., 1991; Apel et al., 2009). The purpose of this paper is to present an overview of the effects of the nervous system on the inorganic component of bone tissue and teeth. We assume that the transection of IAN could be reflected in changed contents 
and distribution of chemical elements in the bone and teeth in the rat mandible. This problem has not been studied so far. At the same time, another purpose is to provide an overview of used experimental models.

\section{Innervation of bone tissue and teeth}

In the first decades of the $20^{\text {th }}$ century, common histological techniques were used to demonstrate the presence of nervous fibres in the periosteum and in the bone. More precise imaging of bone innervation was allowed only with the onset of immunohistochemical analysis. Sensory and autonomic nerve fibres are found in the bone. The pathways of nerve fibres are related specially to blood vessels. More fibres are found in the epiphysis compared to the diaphysis. Branches of periosteal nerves enter cortical bone usually with blood vessels, at the place of Volkmann canals. In the bone the nerves continue in the Haversian canals. These nerves enter the bone marrow and provide rich innervation the osteochondral junction of the growth plate (Lerner et al., 2008). The direct contact of nerve fibres with bone cells indicates the meaning of innervation for the function of bone cells (Chenu, 2004).

Immunohistochemical analysis of the bone have shown the presence of neuropeptides and neurotransmitters in bone tissue. Evidence of the following has been found in the bone with respect to the sensory system for example: substance $P$ and CGRP (calcitonin gene-related peptide). Representative of the autonomic system is for example VIP (vasoactive intestinal peptide). The nervous system can exert an action on the bone metabolism through the presence of receptors on osteoclasts and osteoblasts (Lerner et al., 2008).

Neuropeptides such as CGRP and substance $P$ are synthesized in sensory ganglions, and they distribute both centrally and in the peripheral tissue (Yamashiro et al., 2000). CGRP stimulates osteoblast proliferation (Cornish et al., 1999; He et al., 2016). Additionally, a potential effect on osteoclast differentiation and function has been described (Hara-Irie et al., 1996; He et al., 2016). The results of some studies support the hypothesis that CGRP inhibits bone resorption in vitro (Zaidi et al., 1987; Akopian et al., 2000). Nerve fibres containing substance P and CGRP usually enter the bone along blood vessels. At some point they separate and terminate as free nerve endings in the bone marrow. Cortical bone is innervated to a lower extent (Elefteriou, 2005). Blood vessels and nerve fibres enter teeth through the root canal and reach up to the crown part (Lüllmann-Rauch, 2012). Tooth pulp is innervated by sympathetic nerves (which controls vasoconstriction); these nerves enter together with arterioles and sensory nerve fibres, which form a plexus below the odontoblast layer, and continue further to the layer of odontoblasts and dentinal tubules (Standring, 2016) as free nerve endings (Fristad, 1997). The nerve supply of the dentin-pulp complex is mainly made up of A fibres (both delta and beta) and $C$ fibres. They are classified according to their diameter and their conduction velocity. The A fibres are mainly stimulated by an application of cold, producing sharp pain, whereas stimulation of the $C$ fibres produces a dull aching pain. Because 
of their location and arrangement, the $C$ fibres are responsible for referred pain (Abd-Elmeguid and Yu, 2009).

Nerve terminals present in the pulp release various neuropeptides that have an effect on the homeostasis (Fristad, 1997; Byers et al., 2003; Standring, 2016). As reported by Jacobsen and Heyeraas (1996), neuropeptides such as CGRP and substance $\mathrm{P}$ are involved in the formation of dentin.

\section{The inorganic component of bones and teeth}

The bone contains $45 \%$ of mineral substances, $30 \%$ of organic mass and $25 \%$ of water. A major part of the tooth mass is composed of dentin. The crown is composed of dentin and enamel, while cementum is found in the root surface. $95 \%$ of the enamel mass is represented by minerals. Dentin and cementum contain $70 \%$ and $60 \%$ of mineral substances (Lüllmann-Rauch, 2012).

Many studies have described the contents of elements in human bones (Katić et al., 1991; Smrčka, 2005; Zaichick et al., 2009; Zaichick and Zaichick, 2010a, b; Zaichick et al., 2011; Lanocha et al., 2012). Other studies have analyzed elements found in teeth (Curzon and Crocker, 1978; Curzon and Cutress, 1983; Vrbič et al., 1987; Lane and Peach, 1997; Reitznerová et al., 2000; Fischer et al., 2009, 2013; Ghadimi et al., 2013) or focused on elements in animal models (Yamaguchi et al., 1986; Arora et al., 2005; Hirayama et al., 2011; Oliveira et al., 2012; Maciejewska et al., 2014). Other publications describe the meaning of elements with respect to human bone metabolism (Sarko, 2005; Žofková, 2012; Dermience et al., 2015).

Smrčka (2005) studied distribution of elements in the femur and in the tibia of cadavers. He found, that the following elements were gathered in the epiphysis: $\mathrm{Zn}$, $\mathrm{V}, \mathrm{Ni}, \mathrm{Cr}, \mathrm{Pb}, \mathrm{Mn}, \mathrm{Co}, \mathrm{Sn}$, and in the central part of the diaphysis predominated: $\mathrm{Ca}$, $\mathrm{Sr}, \mathrm{Na}$ and $\mathrm{K}$. This fact thus indicates a non-homogeneous distribution of elements in long bones. Based on the study of pre-historic skeletons the author also describes a change of the content of elements $\mathrm{Zn}, \mathrm{Sr}$ and $\mathrm{Pb}$ in the pyramids of petrous bones and the proximal parts of femurs. The increase in concentrations of $\mathrm{Zn}, \mathrm{Sr}$ and $\mathrm{Pb}$ in the pyramids of petrous bones and proximal parts of femurs in the curves related to age resembled the anthropometrically determined stages of growth acceleration. It was demonstrated on the level of inorganic elements seemed evident: 1) acceleration of growth between 0 and 2 years of age; 2) stabilisation of growth between 2 and 10 years of age; 3 ) acceleration of growth between 10 and 15 years of age; 4) stabilisation of growth between 15 and 20 years of age (Smrčka, 2005). In their study Katić et al. (1991) published different distribution of some chemical elements in human temporal bone. Lanocha et al. (2012) analysed the elements: $\mathrm{Zn}, \mathrm{Pb}, \mathrm{Cu}, \mathrm{Cd}$ and $\mathrm{Hg}$ in the bones of the femur head obtained from patients after hip replacement surgery. The authors found out that $\mathrm{Zn}$ had the highest concentration and $\mathrm{Hg}$ the lowest. Zaichick et al. (2011) described effect of age and gender on 59 trace element in human rib. Reitznerová et al. (2000) described different distributions of elements in individual layers of the enamel. The $\mathrm{Cu}, \mathrm{Fe}, \mathrm{Mn}$ and $\mathrm{Zn}$ concentrations in four 
layers of erupted and non-erupted teeth decreased while $\mathrm{Mg}$ and $\mathrm{Sr}$ concentrations increased toward enamel-dentine junction (Reitznerová et al., 2000). Lane and Peach (1997) described concentration of some elements in the human dental enamel depending on gender, age and geographical location. Fischer et al. (2013) described the change in the content of some elements in deciduous teeth depending on age. In their study Ghadimi et al. (2013) stated that the presence of trace elements in enamel could influence its physical properties. In their publication Curzon and Cutress (1983) were concerned with the link between trace elements and tooth disease. Maciejewska et al. (2014) determined the concentrations of $\mathrm{Zn}, \mathrm{Sr}$ and $\mathrm{Fe}$ in rats (age: 7, 14 and 28 days) bone (mandible, skull, femur and tibia) and incisors. $\mathrm{Zn}$ and $\mathrm{Sr}$ concentrations were highest for the youngest individuals and decreased with age of rats, while Fe content was stable in bone matrix for most studied bones. The authors found higher $\mathrm{Zn}$ and $\mathrm{Sr}$ contents in the incisors compared to their contents in the mandible (Maciejewska et al., 2014). Oliveira et al. (2012) report a different $\mathrm{Sr}$ content in the bone and teeth of rats receiving strontium renalate. As reported by the authors, the incisor tooth presented high strontium incorporation levels, with strontium found in both the enamel and dentin along the whole extension of the tooth. The strontium content of the molar tooth was negligible. Distinct regions of the alveolar bone also seemed to present different strontium levels (Oliveira et al., 2012). Arora et al. (2005) determined in their study that high levels of Pb were observed in the superficial regions of enamel and in the dentine directly adjacent to the pulp. Hirayama et al. (2011) determined 29 elements in rat femurs aging from 5 to 113 weeks old. Yamaguchi et al. (1986) study indicates that, of the essential trace metals, zinc can effectively stimulate the bone growth and calcification with comparatively higher dose levels. This suggests a nutritional significance of $\mathrm{Zn}$ on bone growth. In their study Dermience et al. (2015) summed up the importance of 30 elements for bone metabolism. The constituent part of Žofková's publication (2012) is the significance of trace elements for bone metabolism.

Animal models are commonly used in the study of the inorganic component of bone tissue and teeth (Maciejewska et al., 2014). For example, as reported by Wang et al. (2001), the rat is appropriate for the study of osteoporosis in men as its bone remodelation is similar to that of humans. Bone strength is affected by the bone matrix volume and the microarchitectural distribution of this volume, and by the grade of mineralization. The grade of mineralization depends on the metabolic condition of the entire organism, not only on physical and chemical processes at the place of mineralization (Maciejewska et al., 2014). Various papers have focused on determining mandibular bone mineralization, for example, depending on its load (Tanaka et al., 2007; de Jong et al., 2013; Hichijo et al., 2015).

Hichijo et al. (2015) stated that the lower jaw showed a lower degree of mineralization in the ramus than in the corpus. In the soft-diet group, mineralization below the molars was increased compared to the hard diet group. Analysis showed inhibited growth of the ramus in the soft-diet group (Hichijo et al., 2015). The 
higher mineral density in the corpus than in the ramus in rabbits was also stated in their study by de Jong et al. (2013). The difference of the mineralization in the mandible and at the same time importance of proper masticatory muscle function for craniofacial growth and development described Tanaka et al. (2007).

As reported by Zaichick and Zaichick (2010a), the knowledge of chemical elements contained in bones is essential to understand the aetiology and pathogenesis of bone diseases including osteoporosis. Mineral bone density of the mandible is important for osseointegration of dental implants and has an impact on the prognosis of periodontal disease (Buyukkaplan and Guldag, 2012). At the same time, reduced mineral bone density is associated with an increased risk of tooth loss (Krall et al., 1996). Trace elements in tooth enamel have been investigated for their role in caries and it was found that the presence of $\mathrm{F}, \mathrm{Al}, \mathrm{Fe}$, Se and $\mathrm{Sr}$ is associated with a low risk of tooth caries, while $\mathrm{Mn}, \mathrm{Cu}$, and $\mathrm{Cd}$ have been associated with a high risk (Curzon and Crocker, 1978).

\section{Experimental denervation}

Studies focused on the effect of the nervous system on the bone have been done using various experimental models. Various methods can be used to make a sensory lesion, and causing a chemical lesion to the nerve is one of available options. In this respect, capsaicin has been commonly used (Hill et al., 1991; Adam et al., 2000; Offley et al., 2005; Apel et al., 2009; Ding et al., 2010; Kassab et al., 2013; Heffner et al., 2014). The transection of IAN is another option to achieve only a sensory lesion (Stewart, 1965; Retief and Dreyer, 1969; Torneck and Harnett, 1971; Hoffman and Tade, 1972). Hill et al. (1991) described reduced alveolar bone resorption after tooth extraction in animals receiving capsaicin since their birth. Similar results were reported by Adam et al. (2000). On the other hand, Offley et al. (2005) reported that capsaicin caused reduced levels of substance $P$ and CGRP. Denervation using capsaicin leads to a loss of trabecular bone integrity, to reduction of bone mass and to a decrease in its strength. Additionally, it increases the number of osteoclasts, impairs osteoblast activity and new bone formation. Capsaicin causes a selective lesion to unmyelinated sensory neurons (Offley et al., 2005). In their study, Ding et al. (2010) described different results from those reported by Hill et al. (1991), Adam et al. (2000) and Offley et al. (2005).

A different capsaicin dose, different part of the studied bone and different animal age were considered as possible causes by Ding et al. (2010). As reported by the authors, sensory denervation caused by capsaicin increases bone resorption. As follows from the results, sensory innervation contributes to maintaining trabecular bone mass and mechanical properties through the inhibition of bone resorption (Ding et al., 2010). Apel et al. (2009) studied the effect of sensory denervation on the healing of a femoral fracture in the rat. These authors used locally applied capsaicin for sensory denervation. As shown by mechanical tests, sensory denervation of the bone decreased its resistance against load. The callus cross- 
sectional area was larger for the denervated bone and its density was lower (Apel et al., 2009).

Kassab et al. (2013) published their method of causing a lesion to the IAN, achieving surgical exposure of the nerve using extraoral approach. The lesion was caused to the nerve by local application of capsaicin.

Surgical options for causing only a sensory lesion to a nerve are considerably limited because many peripheral nerves are of mixed nature and contain a motor component, as well. From this point of view, an experimental model with IAN lesion is appropriate. IAN is a sensory nerve that runs through the mandibular canal and contains no motor nerves (He et al., 2010). This nerve provides sensory innervation of mandibular bone and teeth (Nelson, 2015).

The use of experimental lesions to IAN is applied in the study of peripheral and central alterations caused by transection this nerve, by excising its part, by contusing or ligating the nerve. Experimental procedures used to obtain a lesion to IAN have been described by various authors (Stewart, 1965; Retief and Dreyer, 1969; Torneck and Harnett, 1971; Hoffman and Tade, 1972). When the IAN is injured, its distal part degenerates. This is associated with a change in the release of neuropeptides and in the bone metabolism. In this case, not only paresthesia occurs, but a mandibular bone integrity disorder also develops (Wu et al., 2016).

Hiroshima et al. (1998) focused on regenerating periodontal Ruffini ending of the rat incisor in connection with a resection to IAN. This similar problem was studied also by Harada et al. (2003). Yamashiro et al. (2000) described the effect of transection the nerve on bone remodelation during an experimental movement of the teeth. Lv et al. (2014) studied the healing of a periodontal defect and CGRP expression after IAN transection. No statistically significant difference was found in the volume of new bone formation by the authors. A difference was observed in bone mineralization, which was lower in the experimental group. Additionally, the study indicated that the nerve and the CGRP neuropeptide were important factors able to affect the quality of the regenerated alveolar bone through reduction of bone density during the mineralization process (Lv et al., 2014). The effect of causing a transection to the nerve on periodontal tissue regeneration was also studied by Yu et al. (2015). As reported by these authors, innervation influences OPG/RANKL (ostoprotegerin/receptor activator of nuclear factor kappa B ligand) ratio and neuropeptide expression, both of which responsible for periodontal alveolar bone regeneration processes (Yu et al., 2015). He et al. (2010) studied differences in the expression of substance $\mathrm{P}$ in the callus after mandibular osteotomy depending on IAN transection. As reported by these authors, low level of substance $\mathrm{P}$ was a result of IAN amputation and elevation of substance $P$ may be caused by new nerve ingrowth into the bone callus. Substance $P$ is involved in repairing and remodeling the mandible and that involvement of the IAN in the healing process of the mandible may by mediated by neuropeptides, such as substance $P$, which are released by the IAN (He et al., 2010). Ghassemi-Tary and Cua-Benward (1992) described the effect 
of innervation on rat mandibular growth. Jacobsen and Heyeraas (1996) published the effect of capsaicin and of IAN transection on dentin formation in the first molar in the rat. As reported by these authors, capsaicin reduced CGRP and substance P-immunoreactive fibrils in the pulp. The transection of IAN resulted in an almost complete loss of immunoreactive fibrils in the pulp. Dentin formation was reduced in both groups compared to the control group (Jacobsen and Heyeraas, 1996).

Minimum information is found in the literature regarding the effect of sensory innervation on the inorganic bone and teeth component.

\section{Conclusion}

As follows from the literature, bone innervation is substantial for bone growth and remodelling. As indicated by the results of some studies, the distribution and contents of elements in long bones are different in the areas of the diaphysis and epiphysis. Less information is available regarding the distribution of these elements in the mandible. Distribution of chemical elements in the enamel has been described in greater detail. Innervation has an impact on pulp homeostasis. Different rates of mandibular bone mineralization have been described for the rat depending on the load of this bone. Bone mineralization is one of the factors that affect bone strength, healing of bone defects and fractures. It is important for osseointegration of dental implants and it also affects the prognosis of periodontal disease. Chemical elements have an impact on caries occurrence. Based on the literature, a certain effect of sensory innervation of the mandibular bone and teeth on the inorganic component can be assumed. This problem has not been deeply studied so far. IAN transection could be reflected in a change of the contents and distribution of chemical elements in the mandibular bone and teeth. It may be possible to interpret the results with respect to a similar condition in humans. Information learned in this manner could contribute to a better understanding of the effect of IAN on chemical elements in the mandibular bone and teeth. Future studies will focus on the research of effects exerted by IAN on the inorganic component of bones and teeth.

\section{References}

Abd-Elmeguid, A., Yu, D. C. (2009) Dental pulp neurophysiology: Part 1. Clinical and diagnostic implications. J. Can. Dent. Assoc. 75, 55-59.

Abou Neel, E. A., Aljabo, A., Strange, A., Ibrahim, S., Coathup, M., Young, A. M., Bozec, L., Mudera, V. (2016) Demineralization-remineralization dynamics in teeth and bone. Int. J. Nanomedicine 11, 4743-4763.

Adam, C., Llorens, A., Baroukh, B., Cherruau, M., Saffar, J. L. (2000) Effects of capsaicin-induced sensory denervation on osteoclastic resorption in adult rats. Exp. Physiol. 85, 62-66.

Akopian, A., Demulder, A., Ouriaghli, F., Corazza, F., Fondu, P., Bergmann, P. (2000) Effects of CGRP on human osteoclast-like cell formation: a possible connection with the bone loss in neurological disorders? Peptides 21, 559-564.

Apel, P. J., Crane, D., Northam, C. N., Callahan, M., Smith, T. L., Teasdall, R. D. (2009) Effect of selective sensory denervation on fracture-healing: an experimental study of rats. J. Bone Joint Surg. Am. 91, 2886-2895. 
Arora, M., Chan, S. W., Ryan, C. G., Kennedy, B. J., Walker, D. M. (2005) Spatial distribution of lead in enamel and coronal dentine of wistar rats. Biol. Trace Elem. Res. 105, 159-170.

Buyukkaplan, U. S., Guldag, M. U. (2012) Evaluation of mandibular bone mineral density using the dualenergy $\mathrm{X}$-ray absorptiometry technique in edentulous subjects living in an endemic fluorosis region. Dentomaxillofac. Radiol. 41, 405-410.

Byers, M. R., Suzuki, H., Maeda, T. (2003) Dental neuroplasticity, neuro-pulpal interactions, and nerve regeneration. Microsc. Res. Tech. 60, 503-515.

Chenu, C. (2004) Role of innervation in the control of bone remodeling. J. Musculoskelet. Neuronal. Interact. 4, 132-134.

Cornish, J., Callon, K. E., Lin, C. Q., Xiao, C. L., Gamble, G. D., Cooper, G. J., Reid, I. R. (1999) Comparison of the effects of calcitonin gene-related peptide and amylin on osteoblasts. J. Bone Miner. Res. 14, 1302-1309.

Curzon, M. E., Crocker, D. C. (1978) Relationships of trace elements in human tooth enamel to dental caries. Arch. Oral Biol. 23, 647-653.

Curzon, M. E. J., Cutress, T. W. (1983) Trace Elements and Dental Disease. John Wright PSG Inc., Boston. de Jong, W. C., van Ruijven, L. J., Brugman, P., Langenbach, G. E. (2013) Variation of the mineral density in cortical bone may serve to keep strain amplitudes within a physiological range. Bone 55, 391-399.

Dermience, M., Lognay, G., Mathieu, F., Goyens, P. (2015) Effects of thirty elements on bone metabolism. J. Trace Elem. Med. Biol. 32, 86-106.

Ding, Y., Arai, M., Kondo, H., Togari, A. (2010) Effect of capsaicin-induced sensory denervation on bone metabolism in adult rats. Bone 46, 1591-1596.

Elefteriou, F. (2005) Neuronal signaling and the regulation of bone remodeling. Cell. Mol. Life Sci. 62 , 2339-2349.

Elefteriou, F. (2008) Regulation of bone remodeling by the central and peripherial nervous system. Arch. Biochem. Biophys. 473, 231-236.

Elefteriou, F., Campbell, P., Ma, Y. (2014) Control of bone remodeling by the peripheral sympathetic nervous system. Calcif. Tissue Int. 94, 140-151.

Fischer, A., Wiechuła, D., Postek-Stefańska, L., Kwapuliński, J. (2009) Concentrations of metals in maxilla and mandible deciduous and permanent human teeth. Biol. Trace Elem. Res. 132, 19-26.

Fischer, A., Wiechuła, D., Przybyła-Misztela, C. (2013) Changes of concentrations of elements in deciduous teeth with age. Biol. Trace Elem. Res. 154, 427-432.

Fristad, I. (1997) Dental innervation: functions and plasticity after peripheral injury. Acta Odontol. Scand. 55, $236-254$.

García-Castellano, J. M., Díaz-Herrera, P., Morcuende, J. A. (2000) Is bone a target-tissue for the nervous system? New advances on the understanding of their interactions. lowa Orthop. J. 20, 49-58.

Ghadimi, E., Eimar, H., Marelli, B., Nazhat, S. N., Asgharian, M., Vali, H., Tamimi, F. (2013) Trace elements can influence the physical properties of tooth enamel. Springerplus 2, 499.

Ghassemi-Tary, B., Cua-Benward, G. B. J. (1992) The effect of inferior alveolar neurotomy on mandibular growth in the rat. J. Clin. Pediatr. Dent. 17, 19-23.

Harada, F., Hoshino, N., Hanada, K., Kawano, Y., Atsumi, Y., Wakisaka, S., Maeda, T. (2003) The involvement of brain-derived neurotrophic factor (BDNF) in the regeneration of periodontal Ruffini endings following transection of the inferior alveolar nerve. Arch. Histol. Cytol. 66,183-194.

Hara-Irie, F., Amizuka, N., Ozawa, H. (1996) Immunohistochemical and ultrastructural localization of CGRPpositive nerve fibers at the epiphyseal trabecules facing the growth plate of rat femurs. Bone 18, 29-39.

He, H., Tan, Y., Yang, M. (2010) Effect of substance P in mandibular osteotomies after amputation of the inferior alveolar nerve. J. Oral Maxillofac. Surg. 68, 2047-2052.

Effect of Sensory Innervation on the Inorganic Component of Bones and Teeth 
He, H., Chai, J., Zhang, S., Ding, L., Yan, P., Du, W., Yang, Z. (2016) CGRP may regulate bone metabolism through stimulating osteoblast differentiation and inhibiting osteoclast formation. Mol. Med. Rep. 13, 3977-3984.

Heffner, M. A., Anderson, M. J., Yeh, G. C., Genetos, D. C., Christiansen, B. A. (2014) Altered bone development in a mouse model of peripheral sensory nerve inactivation. J. Musculoskelet. Neuronal Interact. 14, 1-9.

Hichijo, N., Tanaka, E., Kawai, N., van Ruijven, L. J., Langenbach, G. E. J. (2015) Effects of decreased occlusal loading during growth on the mandibular bone characteristics. PLoS One 10(6), e0129290.

Hill, E. L., Turner, R., Elde, R. (1991) Effects of neonatal sympathectomy and capsaicin treatment on bone remodeling in rats. Neuroscience 44, 747-755.

Hirayama, M., lijima, S., Iwashita, M., Akiyama, S., Takaku, Y., Yamazaki, M., Omori, T., Yumoto, S., Shimamura, T. (2011) Aging effects of major and trace elements in rat bones and their mutual correlations. J. Trace Elem. Med. Biol. 25, 73-84.

Hiroshima, K., Maeda, T., Hanada, K., Wakisaka, S. (1998) Calretinin-like immunoreactivity in the regenerating periodontal Ruffini endings of the rat incisor following injury to the inferior alveolar nerve. Brain Res. 807, $218-221$.

Hoffman, D. R., Tade, W. H. (1972) Improved technique for sectioning the inferior alveolar nerve in rats. J. Dent. Res. 51, 668.

Jacobsen, E. B., Heyeraas, K. J. (1996) Effect of capsaicin treatment or inferior alveolar nerve resection on dentine formation and calcitonin gene-related peptide- and substance P-immunoreactive nerve fibres in rat molar pulp. Arch. Oral Biol. 41, 1121-1131.

Kassab, A., Hage, M., Jabbur, S. J., Chidiac, J. J. (2013) Modified technique for the exposure of the inferior alveolar nerve in rats. J. Pharmacol. Toxicol. Methods 67, 182-186.

Katić, V., Vujicić, G., Ivanković, D., Stavljenić, A., Vukicević, S. (1991) Distribution of structural and trace elements in human temporal bone. Biol. Trace Elem. Res. 29, 35-43.

Konttinen, Y., Imai, S., Suda, A. (1996) Neuropeptides and the puzzle of bone remodeling. State of the art. Acta Orthop. Scand. 67, 632-639.

Krall, E. A., Garcia, R. I., Dawson-Hughes, B. (1996) Increased risk of tooth loss is related to bone loss at the whole body, hip, and spine. Calcif. Tissue Int. 59, 433-437.

Lane, D. W., Peach, D. F. (1997) Some observations on the trace element concentrations in human dental enamel. Biol. Trace Elem. Res. 60, 1-11.

Lanocha, N., Kalisinska, E., Kosik-Bogacka, D. I., Budis, H., Sokolowski, S., Bohatyrewicz, A. (2012) Concentrations of trace elements in bones of the hip joint from patients after hip replacement surgery. J. Trace Elem. Med. Biol. 26, 20-25.

Lerner, U. H., Persson, E., Lundberg, P. (2008) Kinins and neuro-osteogenic factors. In: Principles of Bone Biology, $3^{\text {rd }}$ Edition. Bilezikian, J. P., Raisz, L. G., Martin, T. J., Pp. 1025-1057, Academic Press, San Diego.

Lüllmann-Rauch, R. (2012) Histologie. Překlad 3. vydání. Grada Publishing, Praha. (in Czech)

Lv, L., Wang, Y., Zhang, J., Zhang, T., Li, S. (2014) Healing of periodontal defects and calcitonin gene related peptide expression following inferior alveolar nerve transection in rats. J. Mol. Histol. 45, 311-320.

Maciejewska, K., Drzazga, Z., Kaszuba, M. (2014) Role of trace elements (Zn, Sr, Fe) in bone development: energy dispersive X-ray fluorescence study of rat bone and tooth tissue. Biofactors 40, 425-435.

Nelson, S. J. (2015) Wheeler's Dental Anatomy, Physiology, and Occlusion, $10^{\text {th }}$ Edition. Elsevier Saunders, St. Louis.

Offley, S. C., Guo, T. Z., Wei, T., Clark, J. D., Vogel, H., Lindsey, D. P., Jacobs, C. R., Yao, W., Lane, N. E., Kingery, W. S. (2005) Capsaicin-sensitive sensory neurons contribute to the maintenance of trabecular bone integrity. J. Bone Miner. Res. 20, 257-267.

Němec I.; Smrčka V.; Pokorný J. 
Oliveira, J. P., Querido, W., Caldas, R. J., Campos, A. P., Abraçado, L. G., Farina, M. (2012) Strontium is incorporated in different levels into bones and teeth of rats treated with strontium ranelate. Calcif. Tissue Int. 91, 186-195.

Patel, M. S., Elefteriou, F. (2007) The new field of neuroskeletal biology. Calcif. Tissue Int. 80, 337-347.

Reitznerová, E., Amarasiriwardena, D., Kopcáková, M., Barnes, R. M. (2000) Determination of some trace elements in human tooth enamel. Fresenius J. Anal. Chem. 367, 748-754.

Retief, D. H., Dreyer, C. J. (1969) Sectioning of the inferior dental nerve in rats. J. Dent. Res. 48, 969.

Sample, S. J., Hao, Z., Wilson, A. P., Muir, P. (2011) Role of calcitonin gene-related peptide in bone repair after cyclic fatigue loading. PLoS One 6, e20386.

Sarko, J. (2005) Bone and mineral metabolism. Emerg. Med. Clin. North Am. 23, 703-721.

Smrčka, V. (2005) Trace Elements in Bone Tissue. Karolinum Press, Praha.

Standring, S. (2016) Gray's Anatomy: The Anatomical Basis of Clinical Practice, Forty-first Edition. Elsevier Limited, New York.

Stewart, J. M. (1965) Sectioning the inferior alveolar nerve in rats. J. Dent. Res. 44, 830.

Tanaka, E., Sano, R., Kawai, N., Langenbach, G. E., Brugman, P., Tanne, K., van Eijden, T. M. (2007) Effect of food consistency on the degree of mineralization in the rat mandible. Ann. Biomed. Eng. 35, 1617-1621.

Torneck, C. D., Harnett, B. (1971) Surgical method for unilateral removal of the inferior dental nerve in the rat. J. Dent. Res. 50, 167.

Vrbič, V., Štupar, J., Byrne, A. R. (1987) Trace element content of primary and permanent tooth enamel. Caries Res. 21, 37-39.

Wang, L., Banu, J., McMahan, C. A., Kalu, D. N. (2001) Male rodent model of age-related bone loss in men. Bone 29, 141-148.

Wilhelm, Z. (2007) Co je dobré vědět o vápníku. Prakt. Lékáren. 4, 184-189.

Wu, Q., Yang, B., Cao, C., Guang, M., Gong, P. (2016) Age-dependent impact of inferior alveolar nerve transection on mandibular bone metabolism and the underlying mechanisms. J. Mol. Histol. 47, 579-586.

Yamaguchi, M., Inamoto, K., Suketa, Y. (1986) Effect of essential trace metals on bone metabolism in weanling rats: comparison with zinc and other metals' actions. Res. Exp. Med. (Berl.) 186, 337-342.

Yamashiro, T., Fujiyama, K., Fujiyoshi, Y., Inaguma, N., Takano-Yamamoto, T. (2000) Inferior alveolar nerve transection inhibits increase in osteoclast appearance during experimental tooth movement. Bone 26, 663-669.

Yu, X., Lv, L., Zhang, J., Zhang, T., Xiao, C., Li, S. (2015) Expression of neuropeptides and bone remodeling-related factors during periodontal tissue regeneration in denervated rats. J. Mol. Histol. 46, 195-203.

Zaichick, S., Zaichick, V. (2010a) The effect of age and gender on 38 chemical element contents in human iliac crest investigated by instrumental neutron activation analysis. J. Trace Elem. Med. Biol. 24, 1-6.

Zaichick, S., Zaichick, V. (2010b) The effect of age and gender on 38 chemical element contents in human femoral neck investigated by instrumental neutron activation analysis. Biol. Trace Elem. Res. 137, 1-12.

Zaichick, S., Zaichick, V., Karandashev, V. K., Moskvina, I. R. (2011) The effect of age and gender on 59 trace-element contents in human rib bone investigated by inductively coupled plasma mass spectrometry. Biol. Trace Elem. Res. 143, 41-57.

Zaichick, V., Zaichick, S., Karandashev, V., Nosenko, S. (2009) The effect of age and gender on Al, B, Ba, Ca, $\mathrm{Cu}, \mathrm{Fe}, \mathrm{K}, \mathrm{Li}, \mathrm{Mg}, \mathrm{Mn}, \mathrm{Na}, \mathrm{P}, \mathrm{S}, \mathrm{Sr}, \mathrm{V}$, and Zn contents in rib bone of healthy humans. Biol. Trace Elem. Res. 129, 107-115.

Zaidi, M., Fuller, K., Bevis, P. J., GainesDas, R. E., Chambers, T. J., Maclntyre, I. (1987) Calcitonin gene-related peptide inhibits osteoclastic bone resorption: a comparative study. Calcif. Tissue Int. 40, 149-154.

Žofková, I. (2012) Osteologie a Kalcium-fosfátový Metabolismus. Grada Publishing, Praha. 